\title{
De taalpolitiek van Willem I
}

\section{LODE WILS}

Een van de middelen die Willem I heeft gebruikt om de Noordelijke en de Zuidelijke Nederlanden duurzaam te verenigen, was zijn taalpolitiek. Ze verdient te worden bestudeerd omdat ze invloed heeft uitgeoefend, ook nog na het mislukken van de vereniging. Maar het blijft nog altijd moeilijk om dit onderwerp in een niet-polemische geest te benaderen ${ }^{1}$.

\section{Staatstaal als bindmiddel onder een verlicht despotisme}

De Franse revolutie had oude staatsvormende krachten als de dynastie en de godsdienst afgeschreven, en deze vervangen door nieuwe: de rechtsgelijkheid van de burgers die allen zouden deelnemen aan het bestuur, de eenvormigheid van de instellingen, taaleenheid door opslorping van de minderheidsgroepen. Napoleon had van de revolutie voltooid en bestendigd hetgeen aanvaardbaar was voor een verlicht absolutist, en Willem I, zoals de andere vorsten van zijn tijd, 's'est couché dans le lit de Napoléon'. Hij bewaarde dus de rechtsgelijkheid maar tegelijk de politieke onmondigheid van de onderdanen, de moderne instellingen, het beginsel van de eenheid van taal in zijn rijk. De Nederlandse taal moest een bindmiddel worden tussen Noord en Zuid.

Concreet betekende dit, dat in die gebieden van België waar de Nederlandse taal volkstaal was, zij alleen gebruikt zou mogen worden in het openbaar leven. Terwijl ze geleidelijk zou worden ingevoerd in de frans- en duitstalige streken, om daar op lange termijn misschien dezelfde rol te gaan spelen als in Friesland.

Deze taalpolitiek verhield zich tot de opkomende nationale stromingen in Europa zoals het verlicht absolutisme zich verhield tot de Verlichting. De nationale bewegingen waren ontvoogdingsbewegingen, onder leiding van burgers en intellectuelen vooral, die aanknoopten bij de nationale tradities van de vóór-absolutistische tijd, welke door de romantiek tot nieuw leven gewekt werden. Hun doel was de volkskrachten wakker te schudden voor een dynamische, democratische, cultureel-geïntegreerde samenleving waarin de volkstaal instrument zou zijn van de 'verlichting' van de hele bevolking, en instrument van een nationaal bestuur dat zou in de plaats komen van de autocratie van de vorst, die dikwijls een vreemdeling was. Zoals andere verlichte absolutisten heeft Willem I aan deze tijdsgedachten vele elementen van zijn politiek ontleend: de krachtige ontwikkeling van het onderwijs; het beroep op die herinneringen uit het nationaal verleden die dienstig waren in de nieuwe situatie; in het Vlaamse land de verheffing van de volkstaal tot enige

1. Veruit het belangrijkste werk is dat van A. de Jonghe, De taalpolitiek van koning Willem I in de Zuidelijke Nederlanden (1814-1830). De genesis der taalbesluiten en hun toepassing (Brussel, 1943). De tweede uitgave (Brugge, 1967) is minder geschikt voor wetenschappelijk gebruik. Het werk van Floris Blauwkuip, De taalbesluiten van koning Willem I (Amsterdam, 1920) blijft onmisbaar omdat het sommige aspecten behandelt die bij De Jonghe niet voorkomen, zoals de letterkundige maatschappijen en het medisch onderricht. 


\section{LODE WILS}

taal voor bestuur, gerecht, lager en middelbaar onderwijs, omkleed met een beroep op de 'volksgeest' en de 'nationaliteit'. Maar in zijn geheel was het politiek bestel van het Verenigd Koninkrijk meer gericht op het smoren van het politiek bewustzijn dan op het nationaal ontwaken ervan.

\section{De verfransing in Vlaanderen}

Het Noorden was maar drie jaar bij Frankrijk ingelijfd geweest en zelfs toen was het nog een administratieve eenheid gebleven. Het herstel van 'de landstaal' schiep er geen moeilijkheden. Maar in het Zuiden lagen de verhoudingen heel anders, en niet alleen in Wallonië waar het Frans zowel bestuurs- als cultuur- en volkstaal was. België was twintig jaar lang volledig ingelijfd geweest en de Franse overheden hadden er een uitroeiingspolitiek gevoerd tegen het Duits (in Luxemburg) en het Nederlands. Ze hadden daarvoor kunnen aanknopen bij het eeuwenoude gebruik van het Frans door de centrale besturen in Brussel, de bekendheid met de taal van de Waalse landgenoten en de Franse buren, de verfransing van de adel. Bovendien stagneerde de ontwikkeling van de volkstaal in de zeventiende en achttiende eeuw tengevolge van het gebruik van Latijn, Spaans en Frans. Die volkstaal bleef een verzameling van sterk verschillende dialecten. Dat alles had het de Franse overheden mogelijk gemaakt om hun taal als de enige op te leggen in bestuur, gerecht, onderwijs en leger, door sommige prefecten zelfs als de enige voor de drukpers en het toneel. De nieuwe administratie, het nieuw gerechtelijk apparaat, de nieuwe bisdommen, die waren allemaal van meet af aan in het Frans opgericht en trouwens grotendeels tengevolge van een doelbewuste benoemingspolitiek - bevolkt met Fransen. De leidende stand, die al vóór 1795 in hoge mate verfranst was, was aangevuld met aanhangers van het Franse regime, opkopers van domeingoederen, zakenlui die veelal uit de vreemde waren toegekomen: zijn taal was het Frans.

In de Vlaamse gewesten kwam het Nederlands na de val van Napoleon niet terug als taal van bestuur, gerecht en middelbaar onderwijs. De ambtenaren, magistraten, bisschoppen, enz., bleven in funktie, met de steun van de nieuwe overheden. Want de geallieerden die tot 15 juli 1814 het land bestuurden, en Willem I daarna, waren vooral erop bedacht de werking van het staatsapparaat niet te bemoeilijken. De wensen van de dekens der ambachten van Brussel, Brugge, Leuven en Gent, om de Franse ambtenaren, wetboeken en taal te zien verdwijnen, werden als onrustzaaiend afgewezen, al waren ze de uitdrukking van wat er leefde bij brede bevolkingslagen. Er werden alleen een paar symbolische toegevingen gedaan aan het gebruik van de volkstaal, inzake de notariële akten, de registratie en de burgerlijke stand. 'Men heeft gemeend het nieuwe rijk ook zonder volksbeweging en zonder volkse medewerking te kunnen stichten. Het is een zeer ernstige fout geweest, welke zich spoedig zou wreken', stelde Leo Picard vast ${ }^{2}$.

Toch was Willem I van meet af aan van plan een taalpolitiek te voeren, en in zijn besluit van 1 oktober 1814 stelde hij nadere bepalingen betreffende de rechtspleging in het vooruitzicht. Maar hij heeft daarmee vijfjaar gewacht.

Waarom heeft er zich intussen geen beweging voorgedaan onder de leidende stand zelf, de notabelen die de stadsbesturen in handen hadden, ambtenaren en advocaten, geestelijken, enz. Dat waren in meerderheid toch mensen uit de streek, die de volkstaal nog gebruikten in hun huiselijke kring, of tenminste in hun omgang met hun dienstboden en met de mindere man die geen andere taal kende. Waarom waren ze niet bereid de relatief

\section{L. Picard, Geschiedenis van de Vlaamsche en Groot-Nederlandsche beweging, I (Antwerpen,} 1937) 137. 
kleine inspanning te doen om zich de kennis van het literair en administratief Nederlands eigen te maken? Cultureel stond Nederland op een dieptepunt tegenover de schitterende Franse expansie. De Zuidnederlandse heren spraken ook liever het Frans dat ze beheersten, dan hun dialect waarin ze zich de minderen voelden van de Noordnederlanders. Maar de kernvraag is: waarom ontstond er in het Vlaamse land niet spontaan een nationale beweging die zich, zoals elders in Europa, toelegde op de ontwikkeling van de volkstaal?

$\mathrm{Al}$ in de achttiende eeuw hadden de Zuidelijke Nederlanden achterstand opgelopen op dit punt, omdat de verspreiding van de modefn-nationale opvattingen uit de Verlichting en de Romantiek er lange tijd was gedwarsboomd door de censuur, en het geestesleven er over het algemeen heel mat was. Tijdens de laatste decennia voor de Franse revolutie was er wel een emancipatiebeweging op gang gekomen, maar die werd grotendeels gesmoord omdat België van 1795 tot 1814 geen satellietstaat van Frankrijk werd, zoals het grootste deel van het vasteland van Europa, maar werd ingelijfd. De aanhangers van de Franse revolutie, die de inlijving toejuichten of voor lief namen omdat het ancien régime er door verdween, moesten wel hun opvatting laten varen dat volkstaal en volksaard essentiële elementen waren voor de ontplooiing van natie en individu. Dat betekende dat de politieke krachten die erfgenaam waren van de revolutie, de liberalen, zoals ze weldra zouden heten, geen stuwers werden van een taalnationalisme, in tegenstelling tot wat elders gebeurde.

Aan traditionalistische, katholieke kant bestond er ook buiten de ambachtelijke kringen wél openheid voor de modern-nationale idee, tenminste voor zover die de nationale tradities en de volkstaal in eer wilde herstellen. Het enige serieuze en invloedrijk katholieke persorgaan, Le Spectateur Belge van de Brugse priester Leo de Foere, pleitte met nadruk en met ongeduld voor een herstel van het Nederlands in het bestuur en het onderwijs in het Vlaamse land. Maar De Foere werd in maart 1817 tot twee jaar hechtenis veroordeeld omdat hij in zijn blad het verzet preekte tegen de eedaflegging op de grondwet. Daarmee zitten we in de kern van het probleem. De volkstaal werd alleen gewaardeerd door diegenen die erin een onderdeel zagen van het nationale erfgoed der Katholieke Nederlanden. $\mathrm{Zij}$ zagen dat erfgoed bijna evenzeer bedreigd door verhollandsing als door verfransing, en konden niet warm lopen voor een Verenigd Koninkrijk dat een voortzetting was van de Napoleontische staat binnen nieuwe grenzen, en met protestantse Hollandse suprematie in plaats van ongelovige Franse. Naar een overeenkomst met deze traditionalistische massa van de bevolking heeft de koning niet gezocht, integendeel hij heeft van de eedkwestie gebruik gemaakt om uit de besturen te weren wie deze visie was toegedaan. Hij rekende erop dat hij zijn vernederlandsing wel zou doorvoeren met degenen wie het om het behoud van de moderne Napoleontische staatsstructuur te doen was; die zouden er de Nederlandse taal wel bijnemen. Hij kreeg gelijk, tenminste op korte termijn.

\section{Het overheidsingrijpen}

Het koninklijk besluit van 15 september 1819 legde in de provincies Oost- en WestVlaanderen, Antwerpen en Limburg aan alle administratieve, rechterlijke en militaire overheden en aan de notarissen de plicht op om met het publiek en met de hun ondergeschikte overheidspersonen of colleges in het Nederlands te handelen als die dat wensten. Pas daarmee kwam een einde aan de opgelegde verfransing, sinds 1795, voor de burgers en de ondergeschikte ambtenaren. Hetzelfde besluit bepaalde dat vanaf 1 januari 1823 het Nederlands de enige ambtelijke taal zou zijn. Pas op 26 oktober 1822 werden die bepalingen ook van toepassing verklaard op de arrondissementen Leuven en Brussel, waar dus 
geen overgangsperiode was voorzien. Nog langer duurde het eer het middelbaar onderwijs werd vernederlandst: vanaf de zomer van 1823 klasse na klasse, zodat pas in 1829 de hervorming voltooid was. In de universiteiten bleef het Latijn de voertaal, met meer uitzonderingen ten gunste van het Frans dan van het Nederlands.

De uitvoering van deze wetgeving bracht geen grote moeilijkheden mee, behalve voor een aantal geïmmigreerde Waalse en Franse ambtenaren en advocaten, en in Brussel. In die hoofdstad was al sinds de achttiende eeuw een hele bovenlaag van de bevolking grondig verfranst. Er moest een overgangsperiode voorzien worden en ook overtredingen geduld. Over het hele land genomen klonken er weinig protesten, maar wel moest van hogerhand worden gewaakt over de toepassing, omdat er van onderop nog altijd geen beweging voor de volkstaal ontstond. Het was vooral de minister van Justitie, Van Maanen, die toezicht hield, en die via de bevordering van ijverige ambtenaren en magistraten het succes verzekerde. Hij was het ook geweest die de koning overtuigd had om krachtig in te grijpen, in plaats van de zaak op de lange baan te schuiven, zoals de Zuidnederlandse ministers De Coninck en Van Gobbelschroy hadden voorgesteld. Hij kon achteraf tevreden zijn. Pas toen vanaf 1828 het Verenigd Koninkrijk in zijn voegen begon te kraken werden de taalbesluiten door de oppositie aangevallen.

Ook bij zijn onderwijspolitiek vergat Willem I de taalproblemen niet: bij de modernisering en uitbreiding van het lager onderwijs werden de volkstalen de voertaal, ook het Duits in Luxemburg. De studie van het Nederlands als vak werd aangemoedigd in heel het Zuidelijk deel van het Rijk, ook in het middelbaar en het hoger onderwijs (Schrant in Gent, Kinker in Luik, Visscher in Leuven). Wanneer de koning persoonlijk ingreep in de bemoeiingen van zijn administratie met onderwijszaken, was het veelal juist in taalaangelegenheden ${ }^{3}$.

Tenslotte bevorderde de regering het ontstaan van letterkundige genootschappen die zich het beoefenen van de landstaal tot doel stelden. Maar die geraakten niet veel verder dan het verenigen van ambtenaren die in een goed blaadje wilden staan bij de overheid. Ook de ondersteuning aan de nederlandstalige boekhandel en pers haalde weinig uit. Het bleef allemaal voor $90 \%$ of méér werk van bovenaf, met heel weinig modern-nationaal ontwaken van onderop. Zelfs in de meeste rederijkerskamers van het Vlaamse land kiemde geen nationale beweging ${ }^{4}$.

\section{Volkstaal in plaats van staatstaal}

In de latere geschiedschrijving lezen we dikwijls dat de taalbesluiten één van de belangrijke oorzaken geweest zijn van de tegenstellingen die het Verenigd Koninkrijk hebben doen uiteenvallen, dat de geestelijkheid de analfabete Vlaamse bevolking liet petitionneren voor het Vlaams tegen het calvinistische Hollands, dat Willem I door zijn besluit van 4 juni 1830 Vlaanderen weer aan de verfransing moest prijsgeven, en dat achteraf gezien De Coninck en Van Gobbelschroy dus gelijk hadden tegen Van Maanen. Het is moeilijk om in kort bestek deze verzameling scheve voorstellingen, overdrijvingen en volslagen vergissingen recht te zetten. Temeer omdat het onderwerp nog altijd gevoelsgeladen is en we dus niet mogen hopen dat zelfs een uitvoerige weerlegging een einde zou maken aan deze mythen.

Er bestond een latente ontevredenheid over de taalbesluiten bij de verfranste stand in het Vlaamse land, beroepshalve vooral bij geïmmigreerde ambtenaren en advocaten. Daar-

3. Ons meegedeeld door prof. M. de Vroede.

4. L. Wils, De ontwikkeling van de gedachteninhoud der Vlaamse beweging tot 1914 (Antwerpen, 1955) $18-23$. 
naast was er een latente vrees in Wallonië voor de uiteindelijke bedoelingen van de koning. Was het Nederlands ook niet in Waalse taalgrensgemeenten opgedrongen? Stuurde Van Maanen aan Waalse instanties geen nederlandstalige brieven waaraan hij alleen een Franse vertaling toevoegde? Waren de rijks lagere scholen in Wallonië, voor de kinderen van ambtenaren en van de gegoede burgerij, niet nederlands- of tweetalig? Weigerde de koning geen franstalige normaalschool en had hij in 1830 niet de bedoeling om er een nederlandstalige te stichten in Luik? Was ook in het leger niet merkbaar dat uiteindelijk het Nederlands als de enige 'landstaal' werd aangezien? Was bij koninklijk besluit van 2 april 1824 niet bepaald dat bij de militaire rechtspraak in Wallonië alleen dan het Frans mocht gebruikt worden, wanneer de belanghebbenden uitsluitend die taal verstonden? Vermits in feite de Walen nog maar weinig hinder ondervonden van Willems taalpolitiek, bestond er ook geen uitgesproken verzet tegen, maar de onrust was er, en terecht.

Toen in 1828 en de volgende jaren de liberale en katholieke opposities zich verenigden om hun lange lijst eisen erdoor te drukken, vooral inzake het parlementair regime en de vrijheid voor de kerk, hebben ze de taalkwestie zoals een aantal andere erbij gevoegd om een extra argument te vinden tegen een gehaat regeringsstelsel, al had die kwestie op zichzelf weinig gewicht ${ }^{5}$. Volgens het beginsel zelf van de unie, allen voor één, vroegen ook de nederlandstaligen taalvrijheid, onder meer in petities uit Zeeland, Noord-Brabant en Gelderland. In de petities uit het Vlaamse land werd meestal uitdrukkelijk vermeld dat de vrijheid voor de Walen gevorderd werd; in slechts enkele werd er ook vrijheid voor het Frans in Vlaanderen gevraagd, en/of het Vlaams tegenover het Hollands gesteld, gekoppeld aan protest tegen de bevoorrechting van de Hollanders inzake benoemingen ${ }^{6}$. Pas door en dus na de revolutie zou er inderdaad een bewegingetje ontstaan om een afzonderlijke Vlaamse taal te scheppen ${ }^{7}$.

Bij twee koninklijke besluiten van 28 augustus 1829, en vooral bij dat van 4 juni 1830 , deed Willem I toegevingen. De Waalse taalgrensgemeenten kregen de taalvrijheid. In Wallonië werd nu uitdrukkelijk het Frans als de officiële taal erkend voor administratieve en gerechtelijke aangelegenheden (niet voor militaire). Facultatief gebruik van het Frans werd toegestaan voor onderhandse en authentieke akten in het hele Rijk. Alleen in het Vlaamse land mochten de rechtbanken en hoven toestaan, dat partijen die het Nederlands 'niet goed' bleken te verstaan, het Frans zouden gebruiken in akten en pleidooien; in strafzaken zou die toestemming niet geweigerd mogen worden. Ook in het Vlaamse land alleen, mochten personen 'die de Nederlandse taal niet verstaan' zich in het Frans tot de

5. P. Hamelius heeft dat al terecht onderstreept in zijn Histoire politique et litéraire du mouvement flamand (Brussel, 1894) 81-84.

6. Een ontleding van de petities bij De Jonghe, Taalpolitiek, 324-325, 347-351.

7. Zie L. Wils, 'Vlaams en Hollands in het Verenigd Koninkrijk', Dietsche Warande en Belfort, (1956) 527-536. Opmerkelijk is dat in de loop van de volgende twintig jaar deze voorstelling de karikatuur alleen heeft kunnen verdringen bij A. W. Willemsen, De Vlaamse Beweging, I (Hasselt, 1974) 32. Onder meer bij H. J. Elias, Geschiedenis van de Vlaamse gedachte, I (Antwerpen, 1963) 285 lezen we nog de gewone propagandistische versie, dat de geestelijkheid aan de ongeletterden of weinig ontwikkelden heeft voorgehouden dat hun taal een vreemde taal was. Zelfs T. Luykx, 'De ontwikkeling van de Vlaamse pers en haar houding tegenover de taalpolitiek van Willem I tijdens het koninkrijk der Nederlanden (1814-1830)', Handelingen Koninklijke Zuidnederlandse Maatschappij Taal- en Letterkunde en Geschiedenis (1973) 224, die een veel genuanceerder beeld geeft, ziet de 'aanvallen op de eenheid van het 'Vlaams' en het 'Hollands' komen uit de hoek van de uitgesproken katholieke oppositiepers, die uit vrees voor het protestantse Noorden een Vlaams-regionalistisch standpunt innam', hoewel de teksten die hij citeert een dergelijke conclusie niet toelaten. 


\section{LODE WILS}

administratieve overheden wenden en deze mochten in dezelfde taal antwoorden. Bekendmakingen mochten, behalve in het Nederlands, ook in het Frans gedaan worden indien dat 'de volkstaal van een deel der bevolking' was. Alles samengenomen werd dus het taalregime ingevoerd dat in België werd gevestigd in 1932. Maar in het centraal bestuur en in het leger bleef het Nederlands overheersen; over het onderwijs werd in de besluiten niet gerept. De oppositie scheen tevreden inzake het taalvraagstuk, voor zover we daarover kunnen oordelen op grond van de weinige maanden die verliepen tussen het besluit van 4 juni 1830 en de opstand.

Hoe is het mogelijk dat een hele reeks auteurs dit besluit voorstellen als het prijsgeven van Vlaanderen aan de verfransing? We zien maar één verklaring: Prayon-van Zuylen, die als eerste dit vraagstuk uitvoerig behandelde, betitelde dat hoofdstuk 'De vrijheid van taal'. Die lapidaire uitdrukking werd door de latere schrijvers overgenomen, zonder dat ze aandacht gaven aan Prayons herhaalde bevestiging

dat de feitelijke vrijheid van taal, welke aan de franssprekende burgers overal waar het behoorde werd verzekerd, geenszins de gelijkstelling van Nederlands en Frans na zich sleepte. Het Frans bleef [in Vlaanderen] een vreemde taal, die, wij kunnen op dit punt niet genoeg drukken, slechts bij uitzondering mocht gebezigd worden. Voor 't overige was bij voortduring de moederspraak énige ambtelijke taal ${ }^{8}$.

Tenslotte was het koninklijk besluit van 4 juni 1830 niet een prijsgeven van Van Maanens voorstel tot onmiddellijke vernederlandsing, voor dat van De Coninck om het langzaam aan te doen. Beide ministers hadden bij de voorbereiding van het besluit van 1819 de staatstaal willen opleggen aan de bevolking. Het besluit van 1830 maakte, net andersom de volkstaal tot overheidstaal, met de nodige uitzonderingen om individuele belangen te ontzien. Zomin De Coninck als Van Maanen hadden daar uit zichzelf aan gedacht.

\section{Gevolgen}

Een van de eerste daden van de revolutie in 1830 was de taalwetgeving af te schaffen. Het Frans werd de taal van het centraal bestuur en van het leger, en verder heerste de vrijheid. Daarvan maakten de provinciale- en stadsbesturen gebruik om hun administratie en hun onderwijs opnieuw te verfransen, zoals de magistraten en advocaten deden met de rechtspraak. Bleef er dan in het Vlaamse land niets over van de verwezenlijkingen van Willem I? Toch wel, en alles samengenomen nog heel wat. Het volksonderwijs bleef nederlandstalig, behalve in Brussel. Op het platteland en in kleine stadjes als Turnhout of Veurne werd ook de gemeentelijke administratie en de rechtspraak in de volkstaal gevoerd. Elders bleef de administratie tweetalig in haar betrekkingen met het publiek. Het middelbaar onderwijs vergleed geleidelijk, van een tweetalig stadium, naar Franse eentaligheid, maar vooral in de colleges van de geestelijkheid op het platteland en in de kleine steden sleepte

8. A. Prayon-van Zuylen, De Belgische taalwetten (Gent, 1892) 94-116 (het citaat op 114). Volgens Blauwkuip, Taalbesluiten, 295, was 'de ganse taalwetgeving ... volkomen teniet gedaan'. Picard, Geschiedenis Vlaamsche en Groot-Nederlandsche beweging, 154-155, 164, meent: 'In 1829 moet men terugkeren tot het uitgangspunt', maar hij ziet toch dat de terugkeer niet volledig is. Het besluit, volgens De Jonghe, Taalpolitiek, 369, 'geeft het Vlaamse land... prijs aan de taal vrijheid, dus aan de verfransing', Elias, Vlaamse beweging, 288 spreekt van 'de afschaffing van de taalwetgeving'. Voor Willemsen, Vlaamse beweging, I, 31, tenslotte 'werd bij K.B. van 4 juni 1830 de taal vrijheid in het Vlaamse land hersteld' en voor T. Luykx 'de onbeperkte taal vrijheid' in: Politieke geschiedenis van België' (Amsterdam-Brussel, 1969) 46. Wij hebben op het onhoudbare van die voorstelling al in 1955 gewezen in De ontwikkeling, 30. 
die ontwikkeling aan tot na 1840. In één woord, het gebruik van de volkstaal was na 1830 veel frekwenter dan in 1814-1819. De kennis ervan, in een vorm die geschikt was voor administratief gebruik, was veel meer verspreid onder de leidende stand en de middengroepen. Ze was veel meer dan tevoren beschaafd en een instrument van beschaving geworden. In die zin kunnen we zeggen dat Willem I een grondslag heeft gelegd voor de latere Vlaamse beweging. Die grondslag zou veel steviger geweest zijn, indien hij van 1814 tot 1819 geen vijfjaar had laten verloren gaan, en in Zuid-Brabant en het middelbaar onderwijs zelfs acht of negen jaar, tot 1822-1823.

Maar de Vlaamse beweging is niet voortgekomen uit het Verenigd Koninkrijk, eerder het tegendeel zelfs. De tegenstelling tussen het Zuiden en het Noorden was er zo scherp, en werd door de koninklijke politiek en de reacties erop zozeer onderhouden, dat het Belgisch nationaal bewustzijn zich krachtig ontwikkelde en zich anti-Nederlands ging uiten. Later zou een strijdend flamingant als L. Vleeschouwer getuigen dat hij uit oppositie tegen Willen I franssprekend was geworden, zoals toen mode was. Ook dat had kunnen vermeden worden indien onder meer de volkse taalregeling van 4 juni 1830 van meet af aan was ingevoerd in plaats van een staatse taalregeling.

Zelfs nog afgezien van de regeringspolitiek die zowel katholieken als liberalen voor het hoofd stootte, was er in het Verenigd Koninkrijk geen plaats voor een nationale beweging in het Vlaamse land die op de Nederlandse taal en volksaard zou zijn gebaseerd. Want de bevolking voelde in haar overgrote meerderheid geen nationale eenheid en geen gemeenschappelijke volksaard met Holland, en wees verhollandsing af. In België zoals elders in Europa omvatte het politiek ontwaken van de bevolking tegen het autoritaire regime van de Restauratievorsten, ook een nationale bewustwording. Die kon niet anders zijn dan Belgisch. Het was uit het nationaal en democratisch enthousiasme van de Belgische revolutie dat een beweging voortkwam om het land tot bloei te brengen door, naar de geest van de tijd, de volkstaal te beoefenen, een nationale kunst en literatuur te scheppen, de geschiedenis te bestuderen, de vaderlandse traditie in ere te houden, enz. Die Belgische beweging, waaruit ook de Frans-Belgische en de Waalse letterkunde een stimulans ontvingen, zou in het Vlaamse land geleidelijk overgaan in een Vlaamse beweging. Literatoren uit het Verenigd Koninkrijk sloten zich daarbij aan, beklemtoonden er de gedachte aan een Nederlandse verbondenheid, en brachten er een piëteitsvolle herinnering in aan Willem I, in wie ze de grondlegger zagen van de Vlaamse herleving. Die visie was niet helemaal onjuist. 


\title{
Onafhankelijkheidspolitiek in agonie. Het oorlogsdagboek van een Hollander
}

\author{
H. W. VON DER DUNK
}

Albert E. Kersten, ed., Het dagboek van dr. G. H. C. Hart. Londen mei 1940-mei 1941 (Werken uitgegeven door het NHG, Vijfde serie VII; Den Haag: Martinus Nijhoff, 1976, 312 blz., $f 49,50)$.

Een groot tekort van het dagboek van dr. G. H. C. Hart is dat het slechts één jaar bestrijkt en in mei 1941 eindigt. Hoe graag zouden we zijn reacties op het wereldgebeuren ook daarna vernemen! Niet omdat hij altijd zo'n feilloos oordeel had maar omdat hij ten prooi viel aan zo interessante vergissingen en illusies. De grote keerpunten van de oorlog: de Duitse aanval op de Sovjet-Unie, Pearl Harbour en de Japanse storm over heel de Pacific, Nederlands-Indië inbegrepen en dan in de jaren 1942 en 1943 het kerende getij. We vernemen niet hoe hij dat alles verwerkt heeft. De uitgever is er blijkbaar ook niet in geslaagd om daarover iets te weten te komen.

Van alle egodocumenten is het dagboek voor de historicus het waardevolst, omdat we hier een mens in zijn onmiddellijke reacties zonder kennis van de afloop betrappen. We zien weer de beperkte horizon van waaruit hij destijds dacht en handelde, die bij alle memoires kunstmatig is verbreed, zo niet vervormd. In Nederland zijn we met politieke dagboeken nog minder gezegend dan met memoires. Maar dat is niet de enige reden, dat men Harts confessies zo geboeid uitleest. Hier stort een man dagelijks zijn ziel op papier uit, die zich opvreet in ballingschap, abrupt gescheiden van vrouw en kinderen, gedoemd tot eindeloze discussies, plannenmakerijen, adviezen aan ministers, die al even machteloos en vleugellam zijn als hij; gedoemd met andere woorden tot verregaande passieve activiteit. Terwijl de bommen maandenlang om hem heen op Londen regenen. De sfeertekening, die hij met deze spontane aantekeningen geeft van de Nederlandse autoriteiten in Londen, evenals van Engeland zelf tijdens dat zo wonderlijke jaar 1940, werpt een verrassend licht op een episode van de tweede wereldoorlog waar nog nauwelijks naar is omgekeken.

Wie was George Henry Charles Hart? Afkomstig uit een welgesteld Joods-Amsterdams gezin studeerde hij rechten en werkte zich na de eerste wereldoorlog als juridisch adviseur van de Suiker Werkgeversbond op Java snel omhoog. Tenslotte werd hij door gouverneurgeneraal De Jonge in 1934 benoemd tot directeur van economische zaken. Hij behoorde tot de delegatie, die in 1934 met Japan over de Japans-Indische handelsproblematiek onderhandelde. In 1937 nam hij ontslag om zuiver familiaire redenen en keerde naar Nederland terug, waar hij aan het departement van koloniën werd verbonden. Als hoofd van de economische afdeling verliet hij op last van zijn minister, Welter, Nederland op 14 mei 1940 om de regering naar Londen te volgen. Het is daaraan dat wij het dagboek te danken hebben.

Het verlangen naar vrouw en kinderen, de tergende zorg over hun lot, slechts door sporadische korte berichten via allerlei omwegen van tijd tot tijd even verlicht, het driftige ongeduld om weer naar een vrij Nederland terug te kunnen, vormen de dominante toon- 